\title{
Efficacy and Safety of Sublingual Immunotherapy for Two Seasons in Patients with Japanese Cedar Pollinosis
}

\author{
Yoshitaka Okamoto $^{a}$ Kimihiro Okubo ${ }^{\text {e }}$ Syuji Yonekura ${ }^{a}$ Kazuhiro Hashiguchi $^{f}$ \\ Minoru Goto ${ }^{g}$ Takashi Otsukam $^{m}$ Tadayuki Murata ${ }^{\mathrm{i}}$ Yuji Nakao

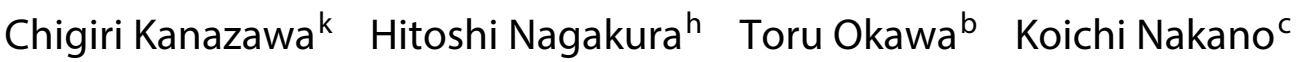 \\ Minako Hisamitsu ${ }^{d}$ Shinya Kaneko' Akiyoshi Konno $^{\text {n }}$ \\ a Department of Otolaryngology, Head and Neck Surgery, Graduate School of Medicine, Chiba University, \\ ${ }^{b}$ Okawa ENT Clinic, ' Nakano ENT Clinic, dDepartment of Otolaryngology, Chiba Kaihin Municipal Hospital, Chiba, \\ e Department of Otolaryngology, Nippon Medical School, ${ }^{\mathrm{f}}$ Futaba Clinic, ${ }^{9}$ Department of Otolaryngology, Nippon

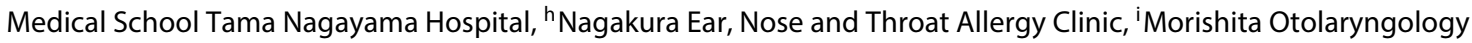 \\ Clinic, jOgikubo Nakao ENT Clinic, and kKanazawa Clinic of Ear Nose Throat, 'Torii Pharmaceutical Co., Ltd., Tokyo, \\ mTokorozawa ENT Clinic, Saitama, and n Otolaryngology Unit, South Tohoku General Hospital, Fukushima, Japan
}

\section{Key Words}

Japanese cedar pollinosis · Pollen extract · Seasonal allergic rhinitis · Sublingual immunotherapy

\footnotetext{
Abstract

Background: Japanese cedar (JC) pollinosis is the most common seasonal allergic rhinitis in Japan. Standardized JC pollen extract is available for subcutaneous immunotherapy, but this treatment is limited by potentially serious side effects. The aim of this double-blind, randomized comparative study was to evaluate the efficacy and safety of standardized JC pollen extract in a new oral formulation (CEDARTOLEN ${ }^{\circledR}$, Torii Pharmaceutical Co., Ltd., Tokyo, Japan) for sublingual immunotherapy (SLIT) for JC pollinosis. Methods: A total of 531 subjects with JC pollinosis were randomized into 2 groups at a ratio of 1:1 to receive daily sublingual administration of standardized JC pollen extract with a maintenance dose of 2,000 Japanese allergy units (JAU) or placebo for
}

2 consecutive pollen seasons. The efficacy was evaluated using the total nasal symptom and medication score (TNSMS) as the primary end point. Secondary end points included the total ocular symptom and medication score (TOSMS) and scores for individual symptoms and medication. Results: The TNSMS was significantly lower $(p<0.0001)$ in the SLIT group than in the placebo group in the peak symptom period by 18 and $30 \%$ in the first and second seasons, respectively. All secondary end points were also significantly lower in the SLIT group in both seasons. No systemic anaphylaxis occurred. Conclusions: SLIT with daily administration of standardized JC pollen extract was effective for improving nasal and ocular symptoms of JC pollinosis and reducing the use of relief medication. The JC pollen extract was well tolerated with only local adverse events.

(c) 2015 S. Karger AG, Basel

Dr. Y. Okamoto and Dr. K. Okubo were the controllers of the study and equally contributed to this study. Dr. A. Konno was the medical advisor.

\section{KARGER 125}

(c) 2015 S. Karger AG, Base

$1018-2438 / 15 / 1663-0177 \$ 39.50 / 0$

E-Mail karger@karger.com

www.karger.com/iaa
Correspondence to: Dr. Yoshitaka Okamoto

Department of Otolaryngology, Head and Neck Surgery

Graduate School of Medicine, Chiba University

1-8-1 Inohana, Chuo-ku, Chiba 260-8670 (Japan)

E-Mail yokamoto@faculty.chiba-u.jp 


\section{Introduction}

In recent years, many countries have had an increase in the prevalence of allergic rhinitis. In Japan, Japanese cedar (JC; Cryptomeria japonica D. Don) pollen is the most important allergen to cause pollinosis. Cedar forests cover nearly $12 \%$ of the total land area of Japan, and produce a large amount of pollen every year. Cedar pollen can travel a long distance and reach major cities, including Tokyo and Osaka, causing widespread pollinosis [15]. Cedar pollen dispersal usually starts in early February and lasts for 10 weeks in the Tokyo area. This is followed by Japanese cypress pollen dispersal, which reaches a peak in early April. JC pollinosis is estimated to affect more than a quarter of the total Japanese population [6].

Treatment of JC pollinois is similar to that for other pollinosis, i.e. symptomatic treatment with antihistamines and nasal corticosteroids. However, this treatment only provides relief from symptoms but does not modify or cure the disease. In contrast, allergen-specific immunotherapy can change the course of the disease. Subcutaneous immunotherapy (SCIT) has been used for JC pollinosis, but is limited by potentially severe systemic adverse effects such as anaphylaxis [7] and pain at the injection site and also requires frequent hospital visits. For these reasons, sublingual immunotherapy (SLIT) has been proposed as an alternative to SCIT. SLIT reduces the burden on patients because the therapy can be administered at home and has fewer severe side effects. The efficacy and safety of SLIT have been shown in double-blind, comparative studies in Europe and North America [811]. This therapy has become a major alternative to SCIT.

Clinical studies of the efficacy and safety of SLIT for JC pollinosis have been conducted in small populations of patients [12-14]. In these studies, standardized JC pollen extract for SCIT was applied in the sublingual cavity and spat out after $2 \mathrm{~min}$. The dosing regimen consisted of an induction phase of 3-4 weeks with increasing doses 5-7 days a week, followed by a maintenance phase with a dose of 2,000 Japanese allergy unit (JAU)/ml once weekly for the rest of the study. Horiguchi et al. [12] and Okubo et al. [13] evaluated the efficacy and safety of SLIT for 7 months in 1 pollen season. They found a significant improvement in QOL scores, but the effects on symptom scores were inconsistent between the two studies. Fujimura et al. [14] used a treatment period of 18 months to cover 2 pollen seasons and observed the carry-over effect in the 3rd pollen season without treatment. Treatment for 18 months had efficacy in the 2 nd pollen season and in the 3 rd season after treatment was terminated, but failed to show a sig- nificant effect in the 1st season [14]. None of the studies showed any serious side effects, such as anaphylaxis.

The differences in results among these studies might be due to the limited number of patients, different treatment periods and variable pollen counts in different seasons. However, despite some inconsistencies, these studies suggest that the sublingual route might indeed be effective for allergen-specific immunotherapy for JC pollinosis. Thus, a formulation (CEDARTOLEN) of standardized JC pollen extract at 200 and 2,000 JAU/ml has been developed for this purpose, using a container with a pump that expels $0.2 \mathrm{ml} /$ push for the induction phase at 200 and 2,000 JAU/ml, and a single-use pouch with $1 \mathrm{ml}$ of 2,000 JAU for the maintenance phase. Using this formulation, we conducted a placebo-controlled, doubleblind, randomized clinical trial on 531 patients with JC pollinosis in order to investigate the long-term efficacy and safety of SLIT using this formulation.

\section{Methods}

\section{Subjects}

The subjects were patients with JC pollinosis who met the inclusion criteria: male or female, an age of 12-64 years, JC-specific immunoglobulin E ( $\mathrm{IgE}$ ) levels (ImmunoCAP) of class 3 or higher and the presence of symptoms of JC pollinosis for the previous 2 years. Patients were excluded who had perennial allergic rhinitis, drug-induced rhinitis, non-allergic rhinitis requiring treatment, had received previous immunotherapy for JC pollinosis, immunotherapy within the previous 5 years, an asthma attack within the previous 5 years or were pregnant.

\section{Study Drugs}

Doses of 200 and 2,000 JAU/ml of JC pollen extract were used in the study. The solution of 200 and 2,000 JAU/ml were formulated by the dilution of standardized JC pollen extract original solution 10,000 $\mathrm{JAU} / \mathrm{ml}(7.3-21 \mathrm{ug} / \mathrm{ml} \mathrm{Cry} \mathrm{j} 1)$ to give the indicated potency, respectively (Torii Pharmaceutical Co. Ltd., Tokyo, Japan). A container with a pump to provide $0.2 \mathrm{ml}$ in one push was used in the induction phase at doses of 200 and 2,000 JAU/ml. A single-use pouch for the maintenance phase was used to deliver $1 \mathrm{ml}$ of $2,000 \mathrm{JAU} / \mathrm{ml}$. The placebo consisted of $50 \%$ glycerine, contained sodium chloride and was similar to the active drug in appearance, taste and smell.

\section{Study Design}

This phase III, multi-centre, randomized, double-blind, placebo-controlled, parallel-group comparative study was started in October 2010. A total of 531 patients with JC pollinosis were recruited from 12 medical institutions in Tokyo and surrounding areas, where the pollen season and JC pollen count were estimated to be similar. Patients were randomized into a JC pollen extract (SLIT) group and a placebo group in a 1:1 allocation ratio. Treatment was given for an average of 18 months from October 2010 to April 2012. The treatment began 4 months before the predicted start of the JC pollen season in 2011 and continued to the end of 
Table 1. Administration schedule of sublingual JC pollen extract

\begin{tabular}{lllll}
\hline & \multicolumn{2}{l}{ Dose-increasing period } & & Maintenance period \\
\cline { 2 - 3 } & $\begin{array}{l}\text { week 1 } \\
\text { 200 JAU/ml }\end{array}$ & $\begin{array}{l}\text { week 2 } \\
2,000 \mathrm{JAU} / \mathrm{ml}\end{array}$ & & $\begin{array}{l}\text { after week 3 } \\
\text { 2,000 JAU/ml }\end{array}$ \\
\hline Day 1 & 0.2 & 0.2 & 1.0 \\
Day 2 & 0.2 & 0.2 & 1.0 \\
Day 3 & 0.4 & 0.4 & 1.0 \\
Day 4 & 0.4 & 0.4 & 1.0 \\
Day 5 & 0.6 & 0.6 & 1.0 \\
Day 6 & 0.8 & 0.8 & 1.0 \\
Day 7 & 1.0 & 1.0 & 1.0 \\
\hline
\end{tabular}

the JC pollen season in 2012. The longest treatment period was 83 weeks. Randomization was performed by CRO (Bell Medical Solutions Inc.). The randomization codes were generated by a trialindependent statistician. To prevent the leakage of information, randomization codes are kept strictly confidential, accessible only to authorized individuals until the time of unblinding.

Patients were instructed to place the study drug under their tongue and to keep it in their mouth for $2 \mathrm{~min}$ before swallowing. They were also requested to place nothing in their mouth and not to gargle for 5 min after swallowing. The dosing schedule comprised an initial 2-week induction period in which the dose was titrated every day from $40 \mathrm{JAU} /$ day to 2,000 JAU/day, followed by a maintenance period at a daily dose of 2,000 JAU/day. The dosing schedule is shown in table 1.

All patients provided written informed consent before inclusion in the study. The study was approved by the institutional review board of each of the 12 participating institutes and was conducted in accordance with the Declaration of Helsinki and Good Clinical Practice guidelines.

\section{Measurement of the JC Pollen Count}

The airborne pollen count was measured with the Durham method [15] at Chiyoda ward in Tokyo by the public service.

\section{Evaluation of Symptoms}

Scores were obtained for nasal symptoms, sneeze, rhinorrhoea and nasal congestion with the use of a 5 -point scale $(0=$ none, $1=$ mild, $2=$ moderate, $3=$ severe and $4=$ very severe) based on the Japanese guidelines for allergic rhinitis [6]. Ocular symptoms (eye itchiness and watery eyes) were scored using a 4 -point scale $(0=$ none, $1=$ mild, $2=$ moderate and 3 = severe).

The periods of evaluation were January 8 to April 30 in 2011 and 2012. Patients were not allowed to use any medicine for the prophylaxis or treatment of JC pollinosis in these periods, including antihistamines or systemic or topical steroids. However, for unbearable symptoms (a nasal symptom with a score of 4 or an ocular symptom with a score of 3 ), a daily dose of the following relief medications was allowed: fexofenadine hydrochloride (a 60mg tablet), tramazoline hydrochloride (a $0.118 \%$ nasal solution) or ketotifen fumarate (a $0.05 \%$ ophthalmic solution). The use of each relief medication was scored as 0 (not used) or 3 (used) and a total drug score was calculated (range: 0-9).

SLIT for Japanese Cedar Pollinosis
Evaluation was performed in each JC pollen season and in each peak symptom period. The pollen season was defined as starting on the first day of the first two consecutive days after January 1 on which there was a pollen count $\geq 1 / \mathrm{cm}^{2} /$ day, and ending on the day before the first of three consecutive days on which there was a pollen count of $0 / \mathrm{cm}^{2} /$ day. The peak symptom period was defined as the week with the worst symptoms based on the sum of nasal symptoms and medication scores for all subjects, plus the weeks before and after this week. To avoid results being confounded by pollens from Japanese cypress, which scatter after the cedar season, the peak symptom period was completed before March 31. During the peak symptom period, subjects completed the Japanese Allergic Rhinitis Quality of Life (QOL) Standard Questionnaire No.1 for the assessment of their QOL [16-18].

\section{Outcome Measures}

The primary end point was the total nasal symptom and medication score (TNSMS; range: 0-18). This score included the nasal symptom scores for sneeze, rhinorrhoea and nasal congestion and the drug scores for fexofenadine tablets and tramazoline nasal spray during the peak symptom period in the 2 nd season.

The secondary end points were the average of the nasal and ocular symptom scores and the drug scores for nasal and ocular use during the peak symptom period in the 1 st and 2nd JC pollen seasons as well as the total ocular symptom and medication score (TOSMS) which included the ocular symptom score (itchiness and watering of eyes) and the drug score for ketotifen ophthalmic solution.

\section{Electronic Diary Records}

Subjects used an electronic diary (Fujitsu Ltd., Tokyo, Japan) to record symptoms (sneeze, rhinorrhoea, nasal congestion, eye itchiness and watery eyes) and use of relief medications from January 8 to April 30 in 2011 and 2012.

\section{Measurement of Serum Immunoglobulins}

Serum IgE, JC pollen-specific IgE and JC pollen-specific IgG4 were measured at 7 time points: before the initiation of dosing and before, in the middle and at the end of the pollen seasons in 2011 and 2012. Assays were conducted at Mitsubishi Chemical Medience (Tokyo, Japan).

\section{Safety}

Adverse effects were categorized as mild (no impact on the activities of daily living), moderate (decreased or affected performance of the activities of daily living) or severe (an inability to perform the activities of daily living or death).

\section{Statistical Analysis}

Based on the results of the clinical study by Fujimura et al. [14] in 2009 , the TNSMS during the peak symptom period were assumed to be 5.8 and 6.8 in the SLIT and placebo groups, respectively, and the standard deviation of the difference between these groups was assumed to be 3.1. Based on these assumptions, the required sample size was 150 subjects in each group with $80 \%$ power and a two-tailed alpha level of 0.05 . However, we anticipated a high number of dropouts because of the prolonged study period which included the continuation of dosing in the season when subjects were asymptomatic. There was also the possibility that JC pollen counts would be lower in 2012 and that subjects would have milder symptoms. For these reasons, a larger study population was 


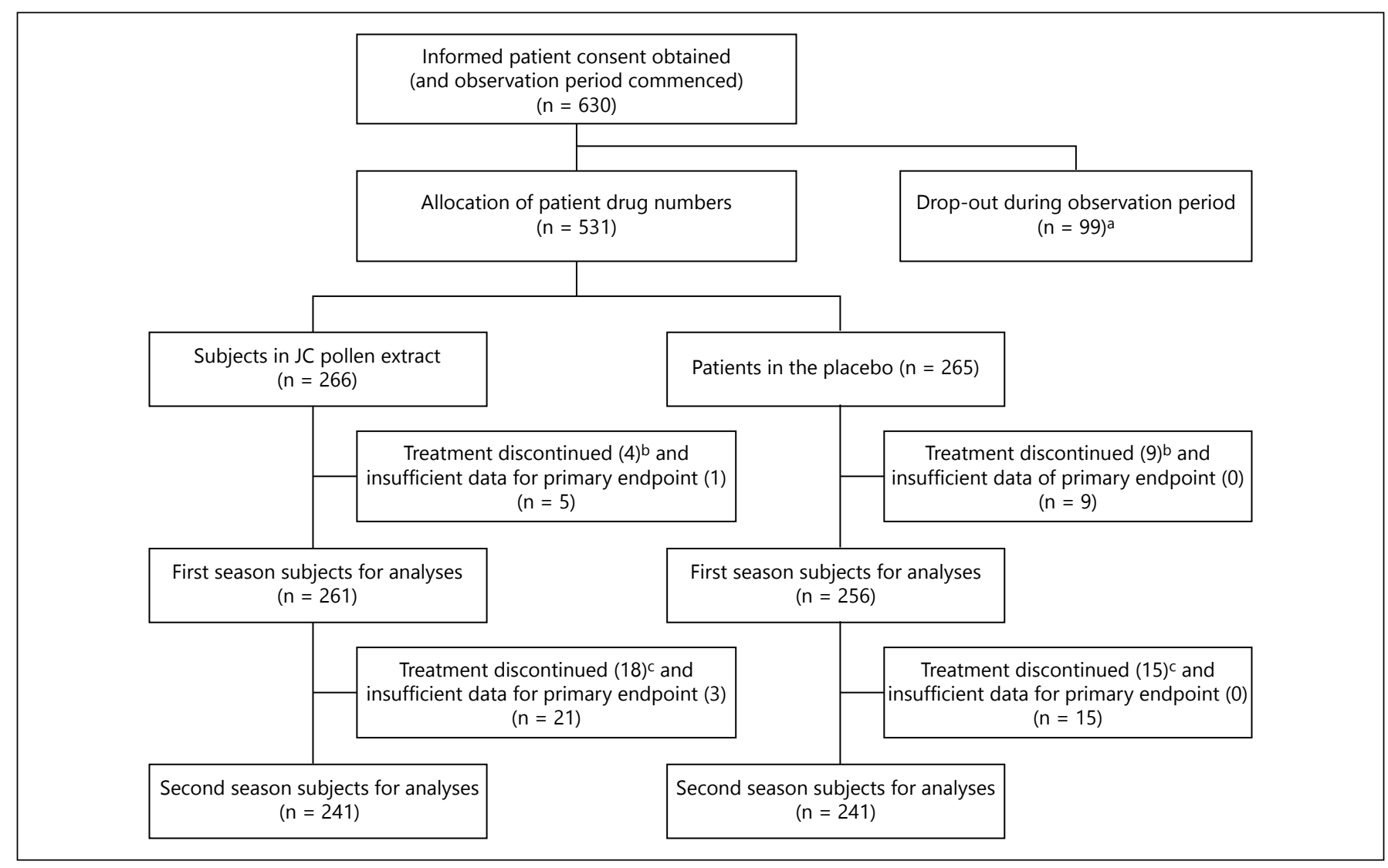

Fig. 1. Flow-chart of the study using SLIT with JC pollen extract. A total of 630 subjects provided written informed consent. Of these subjects, 99 were lost during the observation period and 531 were included in the study and randomized into the SLIT $(n=266)$ and placebo $(n=265)$ groups. The same number of subjects in each group $(\mathrm{n}=241)$ completed the study. ${ }^{\mathrm{a}}$ Drop-out during observation period: 13 subject requests, 51 unmet inclusion criteria and 35 met exclusion criteria. ${ }^{\mathrm{b}}$ First season. Test-drug group: 1 subject request (deteriora-

required to provide sufficient power for analysis, and the target sample size was adjusted to 220 subjects per group.

Data analysis was performed by a biostatistician from Torii Pharmaceutical Co. Ltd. Efficacy analyses were performed on the corresponding modified intent-to-treat analysis set, which was defined as all patients who received at least 1 dose of sublingual JC pollen extract and had at least 50\% TNSMS measurements during the peak symptom period for each season.

For the primary end point, a Student $t$ test was used to compare the average TNSMS between the 2 groups during the peak symptom period in the 2 nd season. The other end points of TNSMS in the 1st season and the TOSMS/drug scores/symptom scores in both the 1st and 2 nd season were analyzed in the same way as the primary end points. Average TNSMS and average TOSMS during the JC pollen season were also analyzed by using a Student $t$ test. The Japanese Allergic Rhinitis QOL Standard Questionnaire No. 1 was analyzed by means of a Wilcoxon rank-sum test. Descriptive statistics were used for demographics and adverse events. tion of disease); 1 subject request (occurrence of adverse effects); 2 personal reasons. Placebo group: 1 subject request (deterioration of disease); 6 personal reasons; 1 inappropriate subject; 1 other reason. ${ }^{c}$ Second season. Test-drug group: 2 adverse effects; 0 subject requests (deterioration of disease); 1 subject request (occurrence of adverse effects); 8 personal reasons; 5 inappropriate subjects; 2 other reasons. Placebo group: 3 subject request (occurrence of adverse effects); 8 personal reasons; 2 inappropriate subjects; 2 other reasons.

Plots of TNSMS and TOSMS by day in both the 1st and 2nd seasons are presented as the mean value with JC pollen count. Plots of JC pollen-specific IgE and JC pollen-specific IgG4 are presented as the mean value with $\mathrm{p}$ values for the changes from baseline to the end of the 2011 season by using a paired Student $t$ test.

\section{Results}

\section{Subjects}

A total of 630 subjects provided written informed consent. Of these subjects, 99 were lost during the observation period and 531 were included in the study and randomized into the SLIT $(n=266)$ and placebo $(n=265)$ groups. A flow-chart of the study is shown in figure 1 . The same number of subjects in each group $(n=241)$ com- 
Table 2. Baseline demographic profile of subjects

\begin{tabular}{lccc}
\hline Factor & JC pollen extract $(\mathrm{n}=266)$ & Placebo $(\mathrm{n}=265)$ & Total $(\mathrm{n}=531)$ \\
\hline Sex & & & $204(38.4)$ \\
$\quad$ Male & $103(38.7)$ & $101(38.1)$ & $327(61.6)$ \\
$\quad$ Female & $163(61.3)$ & $164(61.9)$ & $40.0 \pm 11.1(12-64)$ \\
Age, years & $40.1 \pm 11.9(12-63)$ & $39.8 \pm 10.2(14-64)$ & $162.90 \pm 8.47$ \\
Height, cm & $162.59 \pm 8.65$ & $163.20 \pm 8.29$ & $58.88 \pm 11.52$ \\
Weight, kg & $59.03 \pm 11.96$ & $58.74 \pm 11.09$ & $16.1 \pm 8.8(1-47)$ \\
Disease duration, years & $15.7 \pm 9.1(1-47)$ & $16.6 \pm 8.3(1-40)$ & $327(61.6)$ \\
Family history of pollinosis & & & $204(38.4)$ \\
$\quad$ Yes & $159(59.8)$ & $168(63.4)$ & $225.33 \pm 393.53(10.0-4,800.0)$ \\
$\quad$ No & $107(40.2)$ & $97(36.6)$ & $24.856 \pm 24.875(3.54-100.00)$ \\
Total IgE & $227.14 \pm 431.50(10.0-4,800.0)$ & $223.52 \pm 352.12(13.0-3,200.0)$ & $0.282 \pm 0.585(0.00-4.15)$ \\
JC pollen-specific IgE & $24.665 \pm 24.542(3.61-100.00)$ & $25.047 \pm 25.250(3.54-100.00)$ & \\
JC pollen-specific IgG4 & $0.317 \pm 0.616(0.00-3.92)$ & $0.247 \pm 0.551(0.00-4.15)$ & \\
JC pollen-specific IgE & $152(57.1)$ & & $136(51.3)$ \\
Class 3 & $79(29.7)$ & $94(35.5)$ & $288(54.2)$ \\
Class 4 & $24(9.0)$ & $22(8.3)$ & $173(32.6)$ \\
Class 5 & $11(4.1)$ & $13(4.9)$ & $46(8.7)$ \\
Class 6 & & & $24(4.5)$ \\
\hline
\end{tabular}

Values represent $\mathrm{n}(\%)$ or mean $\pm \mathrm{SD}$ (min.-max.).

pleted the study. The baseline demographic characteristics of the subjects are shown in table 2 . There were no significant differences between the groups.

\section{JC Pollen Counts and Evaluation Period}

Treatment was started at an average of 4 months before the expected start of the $2011 \mathrm{JC}$ pollen season. The pre-season treatment period ranged from 9 to 20 weeks. In 2011, a large amount of JC pollen was scattered and the total pollen count was $6,537 / \mathrm{cm}^{2}$. The JC pollen season (89 days) lasted from February 17 to May 16, and the peak symptom period was from March 7 to March 27. In 2012, the amount of JC pollen was smaller, with a total count of $1,256 / \mathrm{cm}^{2}$. The JC pollen season (56 days) lasted from March 3 to April 27, and the peak symptom period was March 19 to March 31. The mean pollen count in Tokyo in the last 10 years was $3,200 / \mathrm{cm}^{2}$.

\section{Efficacy of SLIT with JC Pollen Extract}

The mean TNSMS and TOSMS scores in the 2011 and 2012 JC pollen seasons are shown in figure 2 . The primary end point (mean TNSMS) was significantly lower in the SLIT group than in the placebo group in the 2012 peak symptom period (4.00 vs. 5.71; p < 0.0001). Similarly, the mean TNSMS in the SLIT group was significantly lower than in the placebo group in the other evaluation periods in the JC pollen seasons of 2011 and 2012 and in the 2011 peak symptom period $(\mathrm{p}<0.0001$; table 3$)$. The SLIT group had significantly lower TOSMS, symptom scores and medication scores than the placebo group for all items in all periods (table 3). A greater improvement in each end point in the SLIT group compared to the placebo group was recorded in the 2 nd season. The respective percentages of patients with TNSMS $<4$ points during the peak pollen dispersal season in the SLIT and placebo groups were 19.9 and $12.1 \%$ in 2011 , and 61.0 and $39.4 \%$ in 2012 (table 4). The total QOL score was also significantly ameliorated in the SLIT group at the peak of pollen dispersal in 2012 (table 5).

\section{Serum Immunoglobulins}

Serum levels of JC pollen-specific IgE and JC pollenspecific IgG4 are shown in figure 3. The JC-specific IgE level increased significantly by up to twice the baseline level 2 months after the start of treatment. The elevated level of JC-specific IgE persisted until the end of the 1st pollen season. In the 2 nd season, this level decreased but at the end, it was still higher than at baseline. The serum level of JC-specific IgG4 increased significantly to 5 times the baseline level after the 2011 JC pollen season. This level gradually decreased until the end of the 2 nd season, but was then still higher than at baseline. Neither the JC-specific IgE nor JC-specific IgG4 level correlated with severity of symptoms or efficacy of treatment (data not shown). 


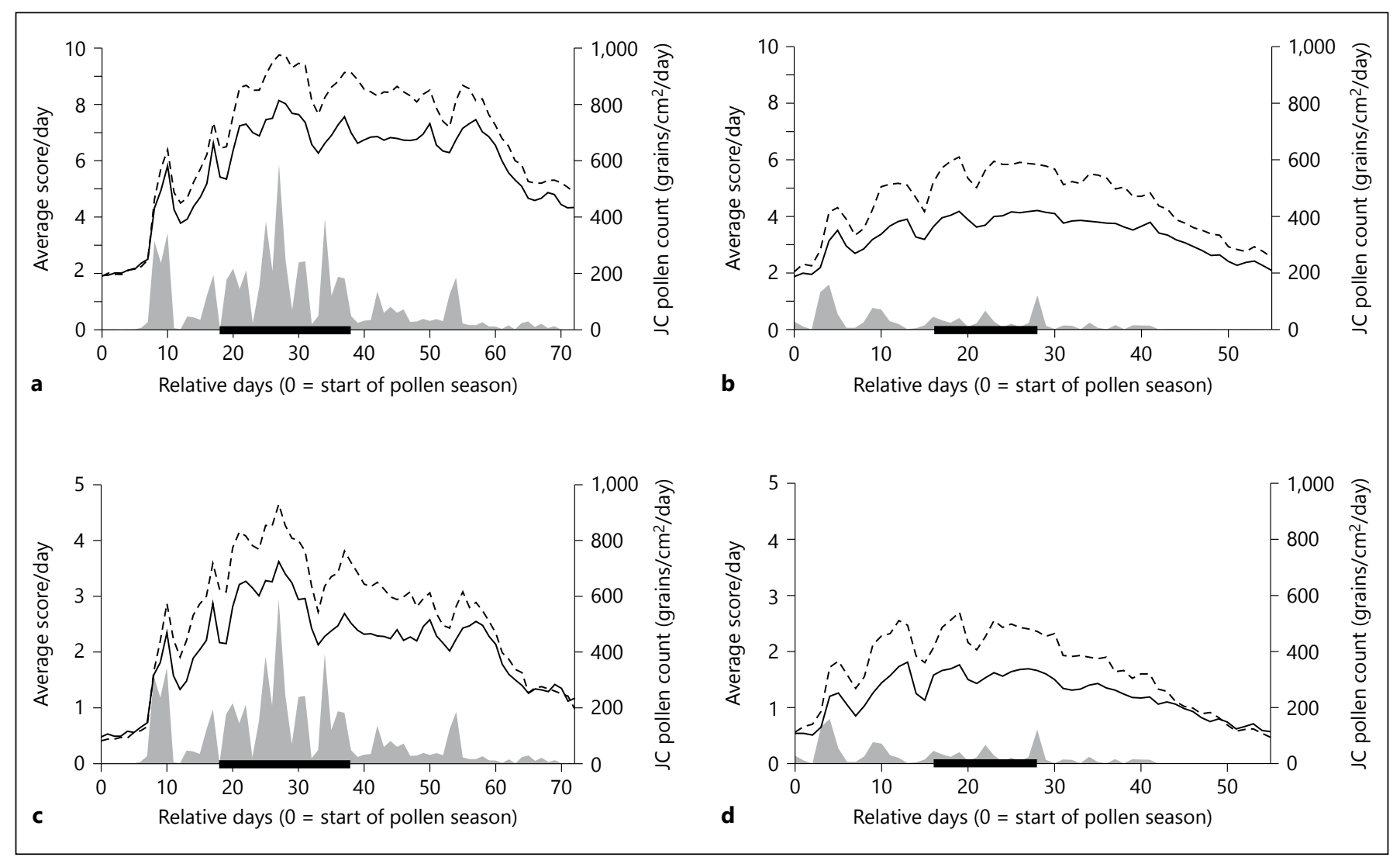

Fig. 2. TNSMS and TOSMS in 2011 and 2012. a TNSMS (2011). b TNSMS (2012). c TOSMS (2011). d TOSMS (2012).The placebo group is represented by the dotted line, the SLIT group by the solid line, the JC pollen count by grey shading and the peak symptom period in black.

The average ratio of JC-specific IgE to total $\operatorname{IgE}$ ( $\operatorname{sgE} /$ tIgE) prior to treatment was 0.18 in all patients in the study. The SLIT group was divided into subgroups with sIgE/tIgE ratios of $\geq 0.18$ and $<0.18$. Similar subgroups were established in the placebo group. The TNSMS in the 2012 peak pollen season in each low sIgE/tIgE subgroup was significantly lower than that in the respective high sIgE/tIgE subgroup, but with no difference between the SLIT and placebo groups (fig. 4).

\section{Safety}

There were 7 serious adverse events in the SLIT group and 6 in the placebo group, with no causal relationship between any of these events and the JC extract or placebo. At least 1 adverse event occurred in 212 of the 266 subjects $(79.7 \%)$ in the SLIT group and in 189 of the 265 subjects $(71.3 \%)$ in the placebo group. Most of the adverse events were mild and required no treatment. No systemic anaphylactic reactions and no deaths occurred during the study. Treatment-related adverse events occurred in
36 subjects (13.5\%) in the SLIT group and $14(5.3 \%)$ in the placebo group (table 6). In the SLIT group, the most common treatment-related adverse event was mouth oedema (10 subjects) followed by stomatitis, throat irritation, headache, oral pruritus and ear pruritus (table 7). Mouth oedema did not occur in the placebo group. The treatment-related adverse events were mild $(n=49)$ or moderate $(n=3)$. None were severe. Adverse effects (except for severe adverse effects) leading to discontinuation of the study occurred in 4 subjects in the SLIT group and in 1 in the placebo group. Of these, a toxic eruption in 1 subject in the SLIT group was identified as a treatmentrelated adverse event.

\section{Discussion}

This is the first, large, randomized, multi-centre, placebo-controlled, double-blind, parallel-group study of the efficacy and safety of SLIT using a new formulation of 
Table 3. TNSMS, TOSMS and scores for each item in the 2011 and 2012 JC pollen seasons

\begin{tabular}{|c|c|c|c|c|c|c|c|}
\hline Item & Year & $\begin{array}{l}\text { Evaluation } \\
\text { period } \\
(\mathrm{A} \text { or } \mathrm{B})^{\mathrm{a}}\end{array}$ & $\begin{array}{l}\text { Mean score } \\
\text { with JC } \\
\text { pollen extract }\end{array}$ & $\begin{array}{l}\text { Mean score } \\
\text { with placebo }\end{array}$ & $\begin{array}{l}\text { Difference } \\
\text { of means } \\
(95 \% \mathrm{CI})\end{array}$ & $\begin{array}{l}\text { Relative } \\
\text { difference }\end{array}$ & $\mathrm{p}$ value \\
\hline \multirow{2}{*}{ TNSMS } & 2011 & $\mathrm{~B}$ & 5.77 & 6.85 & $-1.08(-1.62$ to -0.54$)$ & $16 \%$ & $<0.0001$ \\
\hline & 2012 & A & 4.00 & 5.71 & $-1.71(-2.31$ to -1.11$)$ & $30 \%$ & $<0.0001$ \\
\hline \multirow[t]{4}{*}{ TOSMS } & \multirow[t]{2}{*}{2011} & $\mathrm{~A}$ & 2.82 & 3.75 & $-0.92(-1.30$ to -0.55$)$ & $25 \%$ & $<0.0001$ \\
\hline & & $\mathrm{B}$ & 2.06 & 2.59 & $-0.53(-0.82$ to -0.25$)$ & $21 \%$ & 0.0003 \\
\hline & \multirow[t]{2}{*}{2012} & A & 1.62 & 2.40 & $-0.78(-1.14$ to -0.42$)$ & $32 \%$ & $<0.0001$ \\
\hline & & $\mathrm{B}$ & 1.20 & 1.66 & $-0.46(-0.73$ to -0.18$)$ & $28 \%$ & 0.0011 \\
\hline TNOSMS & 2011 & A & 9.86 & 12.35 & $-2.49(-3.46$ to -1.52$)$ & $20 \%$ & $<0.0001$ \\
\hline \multirow[t]{2}{*}{ Sneeze score ${ }^{b}$} & 2011 & A & 2.21 & 2.52 & $-0.31(-0.47$ to -0.15$)$ & $12 \%$ & 0.0001 \\
\hline & 2012 & A & 1.44 & 1.83 & $-0.39(-0.55$ to -0.24$)$ & $22 \%$ & $<0.0001$ \\
\hline \multirow[t]{2}{*}{ Rhinorrhoea score ${ }^{b}$} & 2011 & $\mathrm{~A}$ & 2.39 & 2.78 & $-0.40(-0.57$ to -0.22$)$ & $14 \%$ & $<0.0001$ \\
\hline & 2012 & A & 1.45 & 2.00 & $-0.55(-0.74$ to -0.37$)$ & $28 \%$ & $<0.0001$ \\
\hline \multirow[t]{2}{*}{ Nasal congestion score ${ }^{c}$} & 2011 & $\mathrm{~A}$ & 1.72 & 2.04 & $-0.32(-0.51$ to -0.13$)$ & $16 \%$ & 0.0009 \\
\hline & 2012 & A & 0.89 & 1.30 & $-0.42(-0.60$ to -0.24$)$ & $32 \%$ & $<0.0001$ \\
\hline \multirow[t]{2}{*}{ Eye itchiness score ${ }^{\mathrm{d}}$} & 2011 & $\mathrm{~A}$ & 1.48 & 1.82 & $-0.35(-0.48$ to -0.21$)$ & $19 \%$ & $<0.0001$ \\
\hline & 2012 & A & 0.90 & 1.30 & $-0.40(-0.55$ to -0.25$)$ & $31 \%$ & $<0.0001$ \\
\hline Watery eyes score ${ }^{\mathrm{d}}$ & 2011 & $\mathrm{~A}$ & 0.90 & 1.13 & $-0.23(-0.36$ to -0.10$)$ & $20 \%$ & 0.0006 \\
\hline Ketotifen score ${ }^{\mathrm{e}}$ & 2012 & A & 0.20 & 0.40 & $-0.20(-0.34$ to -0.07$)$ & $50 \%$ & 0.0032 \\
\hline
\end{tabular}

${ }^{\mathrm{a}} \mathrm{A}=$ peak symptom period + 1 week pre- and post-peak symptom period (7-27 March 2011 and 19-31 March 2012). B = JC pollen season (17 February to 30 April 2011 and 3 March to 27 April 2012).

${ }^{\mathrm{b}}$ Sneeze and rhinorrhoea scores: $0-4$ sneezes $=0 ; 1-5$ sneezes $=1 ; 6-10$ sneezes $=2,11-20$ sneezes $=3 ; \geq 21$ sneezes or more $=4$ [ 1 ]

${ }^{\mathrm{c}}$ Nasal symptom scores (sneeze, rhinorrhoea and nasal congestion): none $=0$; mild $=1$; moderate $=2$; severe $=3$; very severe $=4$.

${ }^{\mathrm{d}}$ Ocular symptom scores (eye itchiness and watery eyes): none $=0 ;$ mild $=1$; moderate $=2$; severe $=3$.

${ }^{\mathrm{e}}$ Drug scores (fexofenadine tablets, tramazoline nasal solution and ketotifen eye solution): not used $=0$; used $=3$.

Table 4. Patients with TNSMS $<4$ points during peak pollen dispersal

\begin{tabular}{lllll}
\hline Item & Year & $\begin{array}{l}\text { Evaluation period } \\
\text { (A or B) }\end{array}$ & $\begin{array}{l}\text { Mean score with } \\
\text { JC pollen extract }\end{array}$ & $\begin{array}{l}\text { Mean score } \\
\text { with placebo }\end{array}$ \\
\hline Number of subjects with TNSMS $<4$ points & 2011 & A & $52(19.9 \%)$ & $31(12.1 \%)$ \\
\cline { 2 - 5 } & 2012 & A & $147(61.0 \%)$ & $95(39.4 \%)$ \\
\hline
\end{tabular}




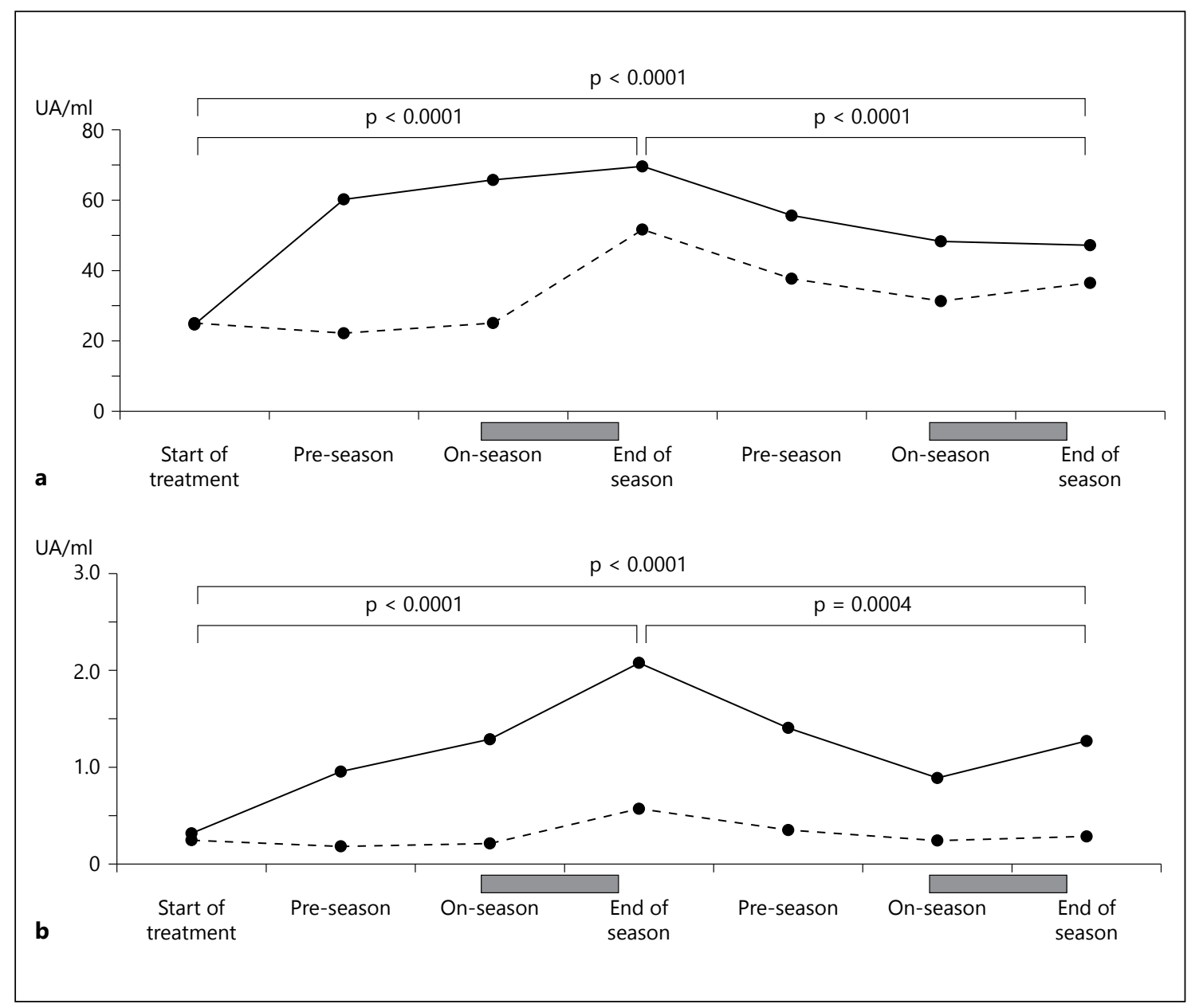

Fig. 3. Serum levels of JC pollen-specific IgE (a) and JC pollen-specific IgG4 (b). The placebo group is represented by the dotted line, the SLIT group by the solid line and the JC pollen scattering period by grey shading.

Table 5. General QOL based on the Japanese Allergic Rhinitis QOL Standard Questionnaire (2nd season)

\begin{tabular}{lrlllll}
\hline General state & 0 (fine) & \multicolumn{1}{l}{ 1 } & 2 & 3 & 4 (watery eyes) & Total \\
\hline JC pollen extract, n (\%) & $13(5.4)$ & $94(39.2)$ & $80(33.3)$ & $45(18.8)$ & $8(3.3)$ & $240(100)$ \\
Placebo, n (\%) & $7(2.9)$ & $54(22.4)$ & $83(34.4)$ & $76(31.5)$ & $21(8.7)$ & $241(100)$ \\
\hline
\end{tabular}

Wilcoxon rank-sum test: $\mathrm{p}<0.0001$.

standardized JC pollen extract for JC pollinosis in Japan. The primary end point, TNSMS in the peak symptom period in the 2nd season (2012), was significantly improved by $30 \%$ in the SLIT group compared with the placebo group, and all secondary end points, including TOSMS, were also significantly improved. The dosing regimen included a daily dose of $2,000 \mathrm{JAU} / \mathrm{mL}$ in the maintenance period after induction, compared to the weekly dose given in this period in previous studies [12-14]. This may underlie the greater improvements in TNSMS, TOSMS and symptom and medication scores in this study compared to previous studies.

Evaluation of the efficacy of treatment for pollinosis is difficult because the amount of scattered pollen and cli- 


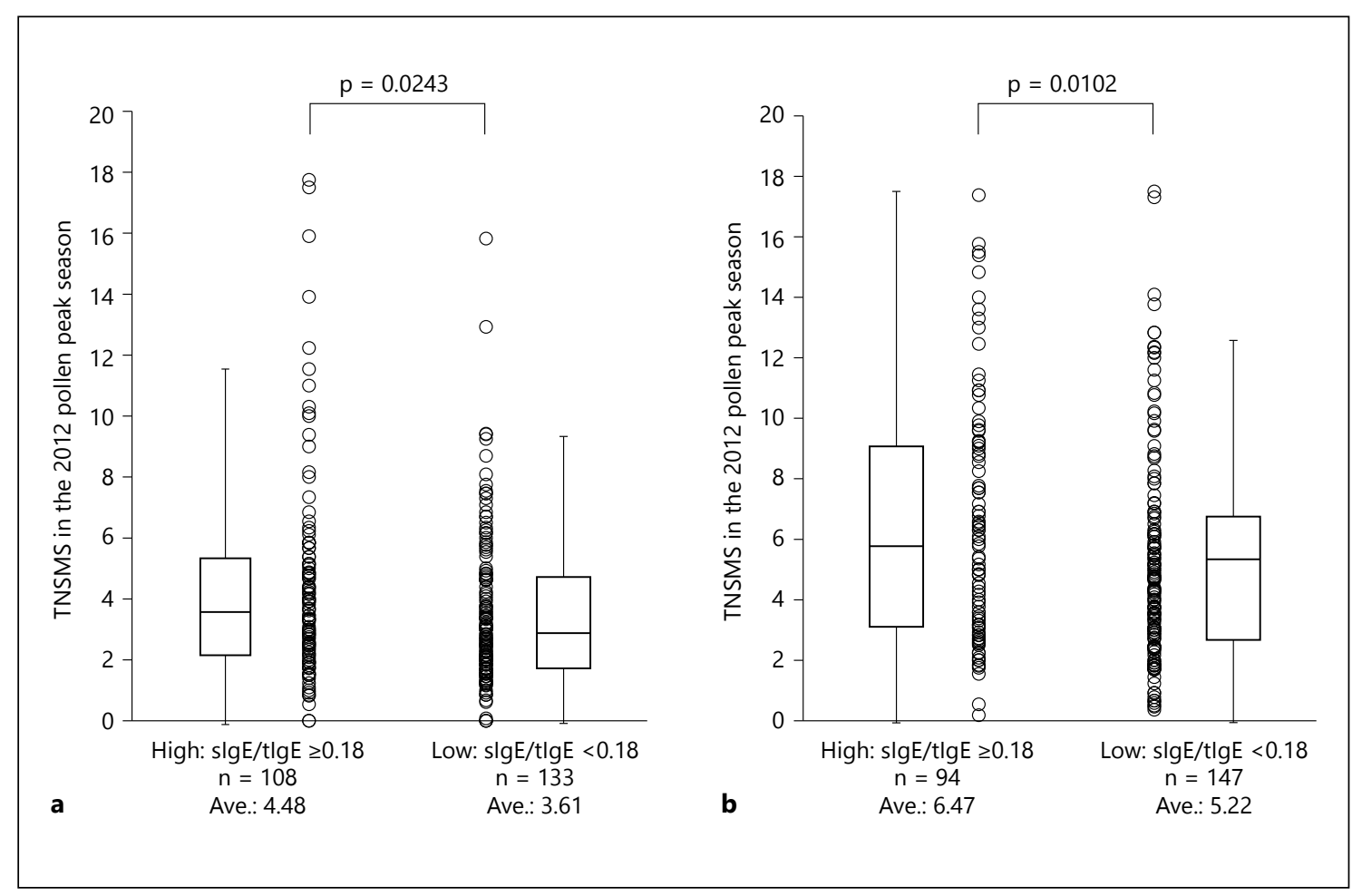

Fig. 4. Relationship of TNSMS in 2012 with the specific IgE/total IgE ratio prior to treatment in the SLIT and placebo groups. a JC pollen extract. b Placebo.

Table 6. Adverse events occurring in patients with JC pollinosis treated with JC pollen extract or placebo

\begin{tabular}{|c|c|c|c|c|}
\hline \multirow[t]{2}{*}{ Summary of adverse events } & \multicolumn{2}{|c|}{ JC pollen extract $(n=266)$} & \multicolumn{2}{|c|}{ Placebo $(\mathrm{n}=265)$} \\
\hline & subjects, n (\%) & events, $\mathrm{n}$ & subjects, n (\%) & events, $\mathrm{n}$ \\
\hline Total of adverse events & $212(79.7)$ & 634 & $189(71.3)$ & 546 \\
\hline Treatment-related adverse events & $36(13.5)$ & 52 & $14(5.3)$ & 27 \\
\hline \multicolumn{5}{|l|}{ Causal relationship } \\
\hline Possible & $11(4.1)$ & 15 & $1(0.4)$ & 2 \\
\hline Probable & $29(10.9)$ & 37 & $13(4.9)$ & 25 \\
\hline Unlikely & $207(77.8)$ & 582 & $187(70.6)$ & 519 \\
\hline \multicolumn{5}{|l|}{ Severity } \\
\hline Mild & $210(78.9)$ & 613 & $186(70.2)$ & 526 \\
\hline Moderate & $16(6.0)$ & 19 & $18(6.8)$ & 20 \\
\hline Severe & $2(0.8)$ & 2 & $0(0.0)$ & 0 \\
\hline
\end{tabular}

matic conditions vary from year to year. In this study, the airborne pollen counts were $6,537 / \mathrm{cm}^{2}$ in 2011 and $1,256 /$ $\mathrm{cm}^{2}$ in 2012, while those in earlier studies were 10,625 / $\mathrm{cm}^{2}$ in 2005 [13], $1,154 / \mathrm{cm}^{2}$ in $2006[12], 2,777 / \mathrm{cm}^{2}$ in

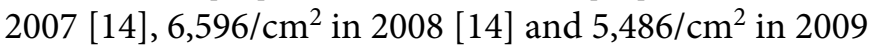
[10]. Based on these data, the airborne pollen counts in this study were within the range of counts in the earlier studies. The pollen count in the 1st season of this study was higher than that in the 1st season in the study by Fujimura et al. [14], but we found significant improvements in symptom and medication scores in this season unlike their findings. The response in our study may have been due to the use of a daily dose of 2,000 JAU/ml in the maintenance period compared to the weekly dose adminis- 
Table 7. Treatment-related adverse events with an incidence of $\geq 1 \%$

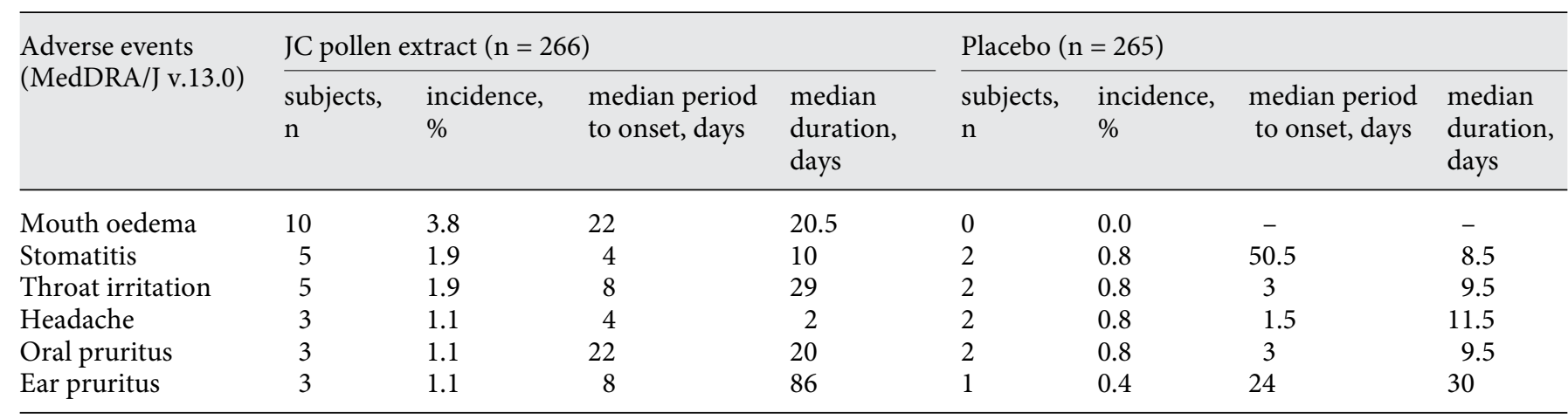

tered in the study by Fujimura et al. [14]. This suggests that daily dosing may improve the immunological response.

Treatment commenced at an average of 4 months before the expected start of JC pollen scattering. Large-scale scattering occurred in the first season, but the SLIT group showed significant improvements in all evaluated items when compared with the placebo group. A large clinical study of grass pollen tablets in Europe [19] and in North America [20] showed that the efficacy of treatment started 4 months in advance of the grass pollen season. Similarly, SLIT with JC pollen extract from 4 months preseason was effective in the 1 st season. We note that TNSMS in the SLIT group showed a greater improvement in the 2nd season than in the 1st. The different JC pollen counts in the 2 seasons make it difficult to compare treatment scores with certainty, and many of the patients in this study were not treated for 4 months prior to pollen dispersal in the 1st season. Recent studies have compared pre-coseasonal, coseasonal and continuous administration of SLIT [10, 21]; however, it is difficult to conclude that continuous treatment over multiple seasons provides better efficacy. Most side effects in our study were mild and were related to the site of administration (mouth oedema, stomatitis and throat irritation). This is also consistent with previous SLIT trials [12-14]. Thus, SLIT with JC pollen extract has an excellent tolerance profile and may be a new treatment of choice for JC pollinosis.

In a large clinical study using sublingual grass pollen tablets [22], the optimal dose of the major allergen was found to be $600 \mu \mathrm{g} / \mathrm{month}$. The maintenance dose used in this study was 2,000 JAU daily, which results in delivery of the major allergens (Cry j 1 and Cry j 2) at doses of $90-150 \mu \mathrm{g} / \mathrm{month}$. At a concentration of $>2,000 \mathrm{JAU} / \mathrm{ml}$, it is difficult to maintain the stability of the cedar pollen liquid extract at $2-8^{\circ} \mathrm{C}$, which is important for ensuring the distribution of the products. Despite this dose being less than the optimal major allergen dose for grass pollen tablets, the dose of JC pollen extract improved TNSMS in the 2 nd season by $30 \%$, comparable to the efficacy in the clinical study of sublingual grass pollen tablets [11]. Thus, the amount of allergen required to treat JC pollinosis was less than that expected in other studies and less than the recommended amount for immunotherapy by the World Allergy Organization. This suggests that JC pollinosis may be a unique case or that a higher dose of JC pollen extract might provide better efficacy. However, it was technically difficult to prepare a solution with a higher concentration of allergen because of the unstable antigenicity of Cry j 1 and Cry j 2 . A cedar pollen tablet with a higher concentration of cedar allergen has recently been developed, and a clinical study to clarify the dose-response relationship is being planned.

Changes in serum immunoglobulins were monitored throughout the study. JC-specific IgE in the placebo group increased after exposure to pollen in the 1st season, but not in the 2 nd. This may be because the pollen count in the 2011 season was 5 times higher than that in 2012. JC-specific IgE increased in the SLIT group before the pollen season, which indicated that the immunotherapy itself affected the Th2-mediated response. The increased IgE levels gradually moved back toward baseline at the end of the 18-month treatment period. Previous studies have found no changes in serum JC-specific IgE. The serum JC-specific IgG4 level gradually increased after the initiation of SLIT, reached a peak at the end of the 1st season and remained at higher levels throughout the study. In contrast, there was no significant change in serum JC-specific IgG4 in the placebo group. The exact 
mechanisms underlying immunotherapy are unclear, but a rebalancing of Th1 and Th2 responses and an increase in IgG4 are among the possible mechanisms. The changes in serum JC-specific IgE and IgG4 in this study may reflect an altered immune response to JC pollen induced by SLIT. The sIgE/tIgE ratio prior to SLIT has been found to be significantly higher [23] or lower [14] in responders compared to non-responders. In this study, this ratio was significantly lower in the responders in the SLIT group, but was also lower in the placebo group in subjects with mild symptoms. Thus, a low $\operatorname{sgE} / \operatorname{tg} E$ ratio prior to the pollen season may be a predictor of mild symptoms in the pollen dispersal season.

The World Health Organization $[24,25]$ recommends a treatment period of 3-5 years for allergen-specific immunotherapy. SLIT using grass pollen tablets has been found to have a disease-modifying effect at the 2-year follow-up after 3 years of treatment [26]. Further data from long-term studies of $>3$ years are required to establish the long-term efficacy and disease-modifying effects of SLIT with JC pollen extract.

\section{Conclusion}

In this 2-year, randomized, placebo-controlled, double-blind study, SLIT with JC pollen extract was effective in the 1st and 2nd JC pollen seasons and was well tolerated.

\section{Acknowledgements}

This study was funded by Torii Co., Inc., Tokyo, Japan. We thank all the participants, coordinators and investigators for their commitment. The study is registered under clinical registration number JapicCTI-101259

\section{References}

1 Okamoto Y, Horiguchi S. Yonekura S, Yamamoto H, Hanazawa T: Present situation of cedar pollinosis in Japan and its immune responses. Allergol Int 2009;58:152-162.

$\checkmark 2$ Okuda M: Epidemiology of Japanese cedar pollinosis throughout Japan. Ann Allergy Asthma Immunol 2003;91:288-296.

3 Ozasa K, Dejima K, Takenaka H: Prevalence of Japanese cedar pollinosis in Japanese school children. Int Arch Allergy Immunol 2002;128:165-167.

-4 Sakashita M, Hirota T, Harada M, Nakamichi R, Tsunoda T, Osawa Y, Kojima A, Okamoto M, Suzuki D, Kubo S, Imoto Y, Nakamura Y, Tamari M, Fujieda S: Prevalence of allergic rhinitis and sensitization to common aeroallergens in a Japanese population. Int Arch Allergy Immunol 2010;151:255-261.

-5 Yonekura S, Okamoto Y, Horiguchi S, Sakurai $\mathrm{D}$, Chazono $\mathrm{H}$, Hanazawa $\mathrm{T}$, Aoki $\mathrm{S}$, Konno A: Effect of aging on the natural history of seasonal allergic rhinitis in middleaged subjects in south Chiba, Japan. Int Arch Allergy Immunol 2012;157:73-80.

-6 Fujieda S, Kurono Y, Okubo K, Ichimura K, Enomoto T, Kawauchi H, Masuyama K, Goto M, Suzuki H, Okamoto Y, Takenaka H: Examination, diagnosis and classification for allergic rhinitis: Japanese guideline. Auris Nasus Larynx 2012;39:553-556.

7 Bernstein DI, Wanner M, Borish L, Liss GM; Immunotherapy Committee, American Academy of Allergy, Asthma and Immunology: Twelve-year survey of fatal reactions to allergen injections and skin testing: 19902001. J Allergy Clin Immunol 2004;113:11291136. $\checkmark 8$ Durham SR, Emminger W, Kapp A, de Monchy JG, Rak S, Scadding GK, Wurtzen PA, Andersen JS, Tholstrup B, Riis B, Dahl R: SQstandardized sublingual grass immunotherapy: confirmation of disease modification 2 years after 3 years of treatment in a randomized trial. J Allergy Clin Immunol 2012;129: 717-725.

-9 Didier A, Worm M, Horak F, Sussman G, de Beaumont O, Le Gall M, Melac M, Malling HJ: Sustained 3-year efficacy of pre- and coseasonal 5-grass-pollen sublingual immunotherapy tablets in patients with grass pollen-induced rhinoconjunctivitis. J Allergy Clin Immunol 2011;128:559-566.

$\checkmark 10$ Nelson HS, Nolte H, Creticos P, Maloney J, Wu J, Bernstein DI: Efficacy and safety of Timothy grass allergy immunotherapy tablet treatment in North American adults. J Allergy Clin Immunol 2011;127:72-80.

11 Cox LS, Casale TB, Nayak AS, Bernstein DI, Creticos PS, Ambroisine L, Melac M, Zeldin RK: Clinical efficacy of 300IR 5-grass pollen sublingual tablet in US study. J Allergy Clin Immunol 2012;130:1327-1334.

12 Horiguchi S, Okamoto Y, Yonekura S, Okawa T, Yamamoto H, Kunii N, Sakurai D, Fujimura T, Nakazawa K, Yasueda $\mathrm{H}$ : A randomized controlled trial of sublingual immunotherapy for Japanese cedar pollinosis. Int Arch Allergy Immunol 2008;146:76-84.

13 Okubo K, Gotoh M, Fujieda S, Okano M, Yoshida $\mathrm{H}$, Morikawa $\mathrm{H}$, Masuyama K, Okamoto $\mathrm{Y}$, Kobayashi M: A randomised doubleblind comparative study of sublingual immunotherapy for cedar pollinosis. Allergol Int 2008;57:265-275.
14 Fujimura T, Yonekura S, Horiguchi S, Taniguchi $\mathrm{Y}$, Saito, A, Yasueda $\mathrm{H}$, Inamine $\mathrm{A}, \mathrm{Na}$ kayama T, Takemori T, Taniguchi M, Sakaguchi $\mathrm{M}$, Okamoto Y: Increase of regulatory T cells and the ratio of specific IgE to total IgE are candidates for response monitoring or prognostic biomarkers in two-year sublingual immunotherapy (SLIT) for Japanese cedar pollinosis. Clin Immunol 2011;139:6574.

15 Durham OC: The volumetric incidence of atmospheric allergens; a proposed standard method of gravity sampling, counting, and volumetric interpolation of results. J Allergy 1946;17:79-86.

16 Okuda M, Ohkubo K, Goto M, Okamoto H, Konno A, Baba K, Ogino S, Enomoto M, Imai T, So N, Ishikawa Y, Takenaka Y, Manndai $\mathrm{T}$, Crawford B: Comparative study of two Japanese rhinoconjunctivitis quality-of-life questionnaires. Acta Otolaryngol 2005; 125 : 736-744.

17 Okuda M, Okubo K, Gotoh M, Okamoto Y, Imano A, Baba K, Ogino T, Ishikawa $\mathrm{K}$, Takenata $\mathrm{Y}$, So $\mathrm{N}$, Imai $\mathrm{T}$, Enomoto $\mathrm{M}$, Mandai T, Crawford B: Standard questionnaire for QOL of Japanese patients with allergic rhinitis. Arerugi 2003;52(suppl 1):2156.

18 Sasaki K, Okamoto Y, Yonekura S, Okawa T, Horiguchi S, Chazono H, Hisamitsu M, Sakurai D, Hanazawa T, Okubo K: Cedar and cypress pollinosis and allergic rhinitis: quality of life effects of early intervention with leukotriene receptor antagonists. Int Arch Allergy Immunol 2009;149:350-358. 
19 Dahl R, Kapp A, Colombo G, de Monchy JG, Rak S, Emminger W, Rivas MF, Ribel M, Durham SR: Efficacy and safety of sublingual immunotherapy with grass allergen tablets for seasonal allergic rhinoconjunctivitis. J Allergy Clin Immunol 2006;118:434-440.

$>20$ Pajno GB, Caminiti L, Crisafulli G, Vita D, Valenzise M, De Luca R, Passalacqua G: Direct comparison between continuous and coseasonal regimen for sublingual immunotherapy in children with grass allergy: a randomized controlled study. Pediatr Allergy Immunol 2011;22:803-807.

-21 Stelmach I, Kaluzinska-Parzyszek I, Jerzynska J, Stelmach P, Stelmach W, Majak P: Comparative effect of pre-coseasonal and continu- ous grass sublingual immunotherapy in children. Allergy 2012;67:312-320.

22 Didier A, Malling HJ, Worm M, Horak F, Jäger S, Montagut A, André C, de Beaumont O, Melac M: Optimal dose, efficacy, and safety of once-daily sublingual immunotherapy with a 5-grass pollen tablet for seasonal allergic rhinitis. J Allergy Clin Immunol 2007;120: 1338-1345.

23 Di Lorenzo G, Mansueto P, Oacor ML, Rizzo M, Castello F, Martinelli N, Ditta V, Lo Bianco C, Leto-Barone MS, D'Alcamo A, Di Fede G, Rini GB, Ditto AM: Evaluation of serum s$\mathrm{IgE} /$ total IgE ratio in predicting clinical responses to allergen-specific immunotherapy. J Allerg Clin Immunol 2009;123:1103-1110.
24 Canonica GW, Bousquet J, Casale T, Lockey $\mathrm{RF}$, Baena-Cagnani CE, Pawanker R, et al: Sub-lingual immunotherapy: World Allergy Organization position paper 2009. World Allergy Organ J 2009;2:233-281.

25 Bousquet J, Lockey R, Malling HJ: Allergen immunotherapy: therapeutic vaccines for allergic diseases. A WHO position paper. J Allergy Clin Immunol 1998;102:558-562.

26 Durham SR, Emminger W, Kapp A, de Monchy JG, Rak S, Scadding GK, Wurtzen PA, Andersen JS, Tholstrup B, Riis B, Dahl R: SQ-standardized sublingual grass immunotherapy: confirmation of disease modification 2 years after 3 years of treatment in a randomized trial. J Allergy Clin Immunol 2012;129:717-725. 